\title{
Variation on Thrombosis detection in neurosurgical patients after updating the perioperative thromboprohylaxis protocol
}

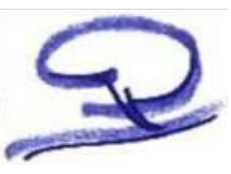

\author{
P. Hurtado, R. Valero, J. Tercero, F. Maldonado, I. Gracia, N. Fàbregas
}

Department of Anaesthesiology and Intensive Care, Hospital Clínic de Barcelona, Barcelona, Spain

phurtado@clinic.cat

\section{Background}

Perioperative thromboprophylaxis strategy for neurosurgical procedures is beyond to be solved and it is a timeless matter of discussion among anaesthesiologists and neurosurgeons.

At the end of 2015 we developed in our hospital a consensus protocol with the neurosurgical team, similar to the latest published recommendations. ${ }^{(1,2)}$

Our aim was to analyse the effect of the protocol on thrombosis prophylaxis, detection and treatment.

\section{Materials and Methods}

Fig 1: Thorax CT reconstruction showing a pulmonary embolism

We retrospectively analysed all electronic database of patients scheduled for neurosurgical intervention before the protocol was implemented (2014-2015) and afterwards (2016). A venous Doppler study was performed in every clinically postoperative thrombosis suspected case.

Patient characteristics (age, sex, BMI), thrombosis location, vena cava filter insertion, pulmonary embolism and any thrombotic event were recorded.

In the new protocol, patients were preoperatively stratified as low, middle and high risk for thrombotic events.

In the new protocol, patients were preoperatively stratified as low, middle and high risk for thrombotic events.

In all levels of risk, graded compression stocking, plus intraoperatively intermittent pneumatic compression, were used during the first 48 hours. In the high risk group, low weight heparin was started 48 hours after surgery in every patient.

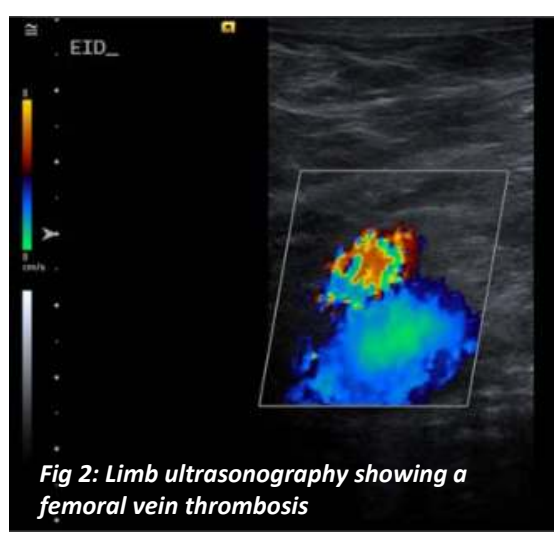

\section{Results and discussion}

In 2014-2015, clinical venous thrombosis was detected and confirmed with venous Doppler in 5 patients out of 435 craniotomies ( $0.9 \%)$; one patient required a vena cava filter placement.

In 2016, 8 patients out of 212 patients who underwent craniotomies (2.6\%) were diagnosed with venous thrombosis after surgery. One patient required a vena cava filter placement; one patient died at home due to a pulmonary thromboembolism 30 days after surgery.

All patients with a thrombotic event were treated with low molecular weight heparin at anticoagulant doses for 3-6 months.

All the patients with thrombosis had been stratified in the high risk category group.

\begin{tabular}{|c|c|c|c|}
\hline Group & $\begin{array}{c}\text { Age } \\
(\mathrm{y} \cdot 0)\end{array}$ & $\begin{array}{c}\text { Gender } \\
(\mathrm{F} / \mathrm{M})\end{array}$ & $\begin{array}{c}\mathrm{BMI} \\
\left(\mathrm{Kg} / \mathrm{m}^{2}\right)\end{array}$ \\
\hline $2014-15$ & $56 \pm 23$ & $4 / 1$ & $25 \pm 6$ \\
\hline 2016 & $79 \pm 11$ & $3 / 5$ & $29 \pm 4$ \\
\hline
\end{tabular}

Table 1: Patient characteristics (mean \pm SD or number of cases)

\begin{tabular}{|c|c|c|c|c|}
\hline Group & $\begin{array}{c}\text { N patients with } \\
\text { thrombotic event }\end{array}$ & $\begin{array}{c}\text { Epilepsy } \\
\text { surgery }\end{array}$ & $\begin{array}{c}\text { Neoplasic } \\
\text { surgery }\end{array}$ & $\begin{array}{c}\text { Aneurysm } \\
\text { clipping }\end{array}$ \\
\hline $\mathbf{2 0 1 4 - 1 5}$ & $\mathbf{5} / \mathbf{4 3 5}$ & 2 & 3 & 0 \\
\hline $\mathbf{2 0 1 6}$ & $\mathbf{8} / \mathbf{2 1 2}$ & 1 & 6 & 1 \\
\hline
\end{tabular}

Table 2: Thrombotic events (number of cases)

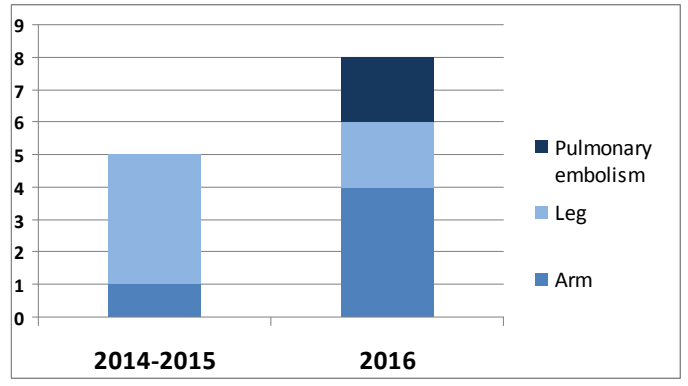

Fig 3: Thrombosis location (Data as number of cases)

\section{Conclusions}

The enforcement of an updated venous thrombosis prophylaxis protocol in neurosurgery patients has increased the awareness of this complication in our hospital and has contribute to an increase number of cases diagnosed.

These results are in accordance with quality and safety health care standards implementation.

\section{References}

1. Vázquez-Alonso E, Iturri Clavero F, Valencia Sola L, Fábregas N, Ingelmo Ingelmo I, Valero R, Cassinello C, Rama-Maceiras P, Jorques A. Clinical practice guideline on thromboprophylaxis and management of anticoagulant and antiplatelet drugs in neurosurgical and neurocritical patients. Rev Esp Anestesiol Reanim. 2016 Aug-Sep;63(7):406-18

2. Faraoni D, Ferrandis R, Geerts W and Wiles MD, for the ESA VTE Guidelines Task Force. European guidelines on perioperative venous thromboembolism prophylaxis. Eur J Anaesthesiol 2017; 34:1-6. 